\title{
Does place of residence affect risk of suicide? a spatial epidemiologic investigation in Kentucky from 1999 to 2008
}

\author{
Daniel M Saman', Sabrina Walsh¹, Anna Borówko² and Agricola Odoi ${ }^{3^{*}}$
}

\begin{abstract}
Background: Approximately 32,000 people take their own lives every year in the United States. In Kentucky, suicide mortality rates have been steadily increasing since 1999. Few studies in the United States have assessed spatial clustering of suicides. The purpose of this study was to identify high-risk clusters of suicide at the county level in Kentucky and assess the characteristics of those suicide cases within the clusters.

Methods: A spatial epidemiological study was undertaken using suicide data for the period January 1, 1999 to December 31, 2008, obtained from the Kentucky Office of Vital Statistics. Descriptive analyses using Pearson's chisquare test and t-test were performed to determine whether differences existed in age, marital status, year, season, and suicide method between males and females, and between cases inside and outside high-risk spatial clusters. Annual age-adjusted cumulative incidence rates were also calculated. Suicide incidence rates were spatially smoothed using the Spatial Empirical Bayesian technique. Kulldorff's spatial scan statistic was applied on all suicide cases at the county level to identify counties with the highest risks of suicide. Temporal cluster analysis was also performed.

Results: There were a total of 5,551 suicide cases in Kentucky from 1999 to 2008, of which 5,237 (94\%) were included in our analyses. The majority of suicide cases were males (82\%). The average age of suicide victims was 45.4 years. Two statistically significant $(p<0.05)$ high-risk spatial clusters, involving 15 counties, were detected. The county level cumulative incidence rate in the most likely high-risk cluster ranged from 12.4 to 21.6 suicides per 100,000 persons. The counties inside both high-risk clusters had relative risks ranging from 1.24 to 1.38 .

Conclusions: Statistically significant high-risk spatial clusters of suicide were detected at the county level. This study may be useful for guiding future research and intervention efforts. Future studies will need to focus on these high-risk clusters to investigate reasons for these occurrences.
\end{abstract}

\section{Background}

Between 2000 and 2007, there were 256,085 deaths in the United States (US) attributed to suicide. Approximately 32,000 people take their own lives every year in the US [1]. In 2009, suicide was the tenth leading cause of death for all ages, the second leading cause of death among 25-34-year olds, and the third leading cause of death among 15-24-year olds [1]. Firearms, suffocation, and poisoning are the most common methods of suicide; however, men and women differ in the methods

\footnotetext{
*Correspondence: aodoi@utk.edu

${ }^{3}$ Department of Biomedical \& Diagnostic Sciences, College of Veterinary

Medicine, University of Tennessee, Knoxville, Tennessee, USA

Full list of author information is available at the end of the article
}

used. In the same year, firearms were the most commonly used methods of suicide among males, while poisoning was the most commonly used mechanism in females. Males died by suicide at nearly four times the rate of females and represented $78.8 \%$ of all US suicides. During their lifetime though, women attempt suicide about two to three times as often as men [1].

In Kentucky, suicide mortality rates have been steadily increasing since 1999. In 2006, suicides rose to 14.4 per 100,000 persons from the 1999 rate of 11.3 per 100,000 persons, a $27 \%$ increase. With an average of 13.4 suicides per 100,000 people annually (2000-2006), Kentucky ranks $16^{\text {th }}$ highest for suicide in the US [1]. Additionally, medical costs and lost wages associated

\section{Biomed Central}


with suicide also take their toll on communities. In 2005 , suicide cost society $\$ 26.7$ billion in combined medical and work loss costs, while in Kentucky it was estimated to cost $\$ 481$ million [2].

A combination of demographic, individual, relational, community, and societal factors contribute to the risk of suicide. According to the World Health Organization's (WHO) report on violence and health, demographic factors such as age and sex, psychiatric, biological, social and environmental factors, as well as factors related to an individual's life history might play a role in making people more likely to attempt or commit suicide [3].

Although much is understood about suicide at the individual level, including multiple factors associated with increased risk of suicide [3], little has been done at the ecologic level to identify counties or neighborhoods with the greatest risk of suicide. Just as determining individual-level risk factors for suicide is vital for suicide prevention efforts, identifying high-risk areas and investigating spatial patterns for suicide provides a richer understanding of the determinants of suicide than the individual-level risk factors alone. Thus, identifying high-risk counties using spatial statistics may allow for a better targeting of resources and suicide intervention efforts so as to prevent future suicides.

Several studies have used spatial statistical techniques in assessing the presence of high-risk clusters including a brain cancer cluster study [4], a study on networks of sexually transmitted infection [5], and on breast cancer mortality disparities [6]. Other studies incorporating similar methodologies have assessed high-risk clusters of La Crosse virus in West Virginia [7], clusters of giardiasis in Canada [8], and clustering of lung cancer in Italy [9]. However, spatial studies of suicide clusters have been limited. Exeter and Boyle (2007) found a significant geographical cluster of suicide among young adults in east Glasgow across three time periods (1980 to 1982, 1990 to 1992 , and 1999 to 2001), which were attributed to socioeconomic deprivation [10]. Another study investigating suicide clusters in Queensland, Australia, found clusters in low socioeconomic areas [11]. These studies provide some support that regions at high risk for suicide are those with greater socioeconomic deprivation.

Though suicide studies have used spatial statistical techniques in other countries, little has been published in the US. The present study has the potential to bridge the gap between suicide research and targeted prevention. The primary purpose of this study was to identify counties at the highest risk for suicide. Secondarily, this study also tests whether suicides are clustered temporally. Thus, the current study provides an analytical framework, using spatial statistics, to identify and target areas with the highest risk of suicide. Further, identification of counties at a greater risk for suicide is expected to guide resources and assist in policy decision making at the county level.

\section{Methods \\ Study design}

This is an ecological study of suicides in Kentucky counties $(n=120)$ from January 1,1999 to December 31,2008 . All the cases of suicide identified in the study occurred in Kentucky. This research was approved by the University of Kentucky Institutional Review Board (IRB \#: 02-0441-p6h).

The Kentucky Office of Vital Statistics provided electronic injury-related death certificate data files from January 1, 1999 to December 31, 2008. A subset of the data was then generated using The International Classification of Diseases, 10th revision (ICD-10) External Causes of Death Codes (X60-X84, Y10-Y34, Y87.0), which meet the Center's for Disease Control and Prevention's (CDC) National Violent Death Reporting System's definition of suicide [12]. Data elements included gender, age, marital status, date of suicide, county of suicide, and suicide method. Several exclusion criteria were applied: 1) cases were first excluded if the underlying cause of death did not match the manner of death; 2) from this set, cases with unknown county of death were excluded; 3) thirdly, any cases where age was unknown were excluded; 4) lastly, cases where the date of death was unknown were also excluded (see Exclusion Criteria in Figure 1). After these cases were excluded, the remaining data set did not have any missing values.

\section{Descriptive statistical analyses}

We used Pearson's chi-square test and two-tailed unequal variance t-tests to determine whether there were significant differences between cases by gender for age, marital status, year, season, and suicide method. Pearson's chi square tests and t-tests were calculated in WinPepi v11.4 [13] and SAS v9.3 (SAS Institute Inc, Cary, NC) [14], respectively.

Age adjusted male and female cumulative incidence rates were directly adjusted using the decennial 2000 United States Census Population. Cumulative incidence rates were expressed as the number of suicides per 100,000 persons for all of Kentucky from 1999 to 2008, and calculated in Microsoft Excel 2007 [15].

\section{Geographic analysis}

Smoothed cumulative incidence suicide rates were mapped at the county level $(n=120)$. The heterogeneity of variances and spatial autocorrelation of suicide rates were adjusted for by smoothing using Spatial Empirical Bayesian (SEB) rate smoothing [16]. This technique is appropriate when population sizes of areas of aggregation vary and there is spatial autocorrelation in the data. Given that population sizes vary by county, suicide rates 


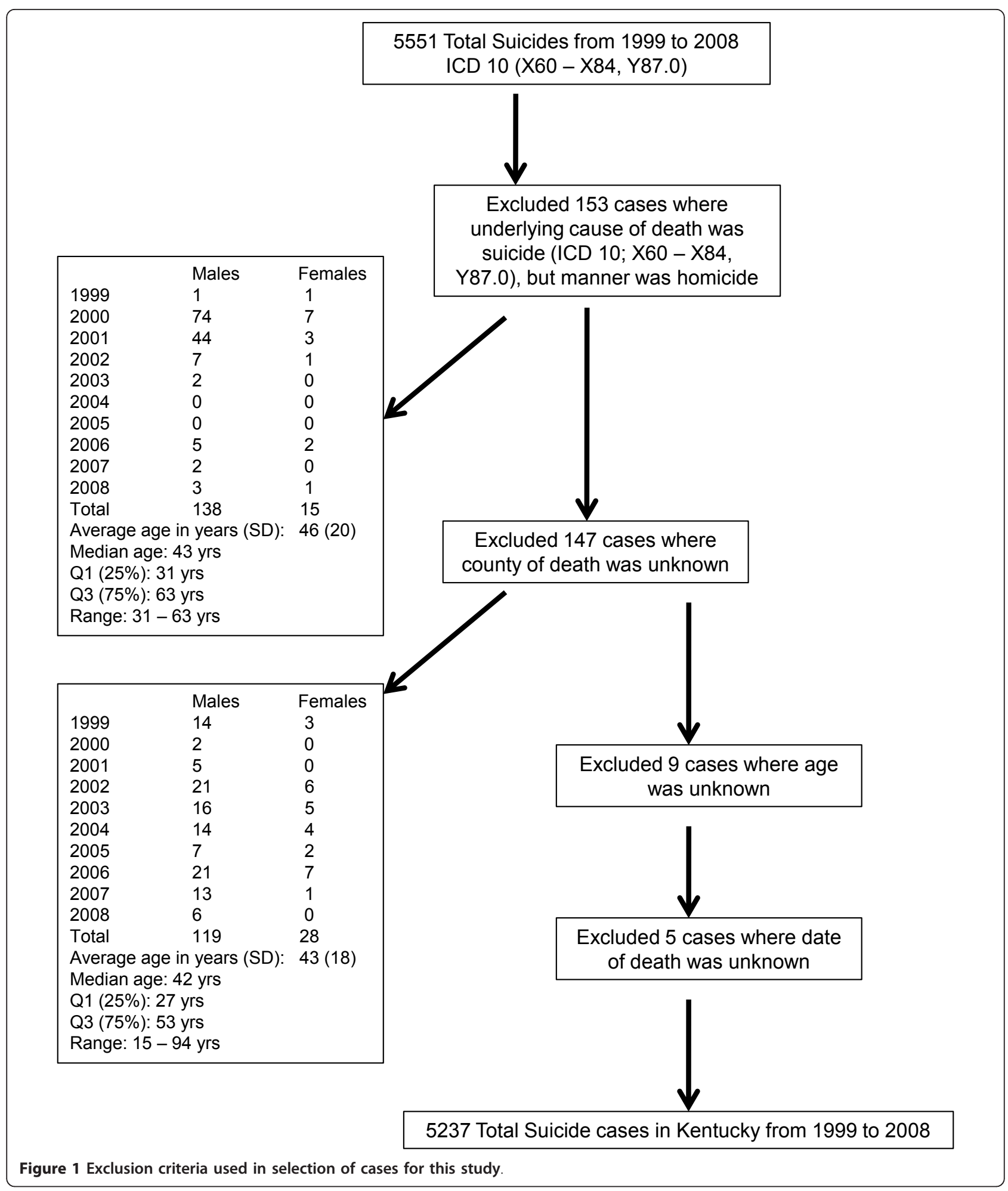

from counties of small population have greater variance than counties with higher populations [17]. This technique was implemented in GeoDa v0.95i [18] using a first-order queen contiguity spatial weights matrix [19].
The geographic boundary file used in this study was downloaded from the United States Census, TIGER, Geodatabase [20]. ArcGIS v10 (ESRI, Inc, Redlands, CA.) [21] was used to create the cartographic displays of smoothed 
incidence rates, with single hue color schemes generated by http://ColorBrewer.org[22]. The SEB smoothed incidence rates were grouped into five classes/categories using the Jenks natural breaks optimization algorithm [23].

\section{Spatial and temporal scan statistical cluster analyses}

The detection of high-risk local spatial clusters of suicide was performed using Kulldorff's 2-dimensional spatial scan statistic [24], and implemented in SaTScan v9.1 [25]. The advantages of using the scan statistic include controlling for covariates, adjusting for multiple comparisons and various population sizes, and limiting preselection bias by not specifying a priori the observed set of cases within a cluster [24,26,27]. Significance testing is performed using Monte Carlo simulation where the null hypothesis of no cluster is rejected at an $\alpha$ level of 0.05 if the simulated pvalue is less than or equal to 0.05 [28]. A significant highrisk cluster is interpreted as having an increased risk of suicide within the circular window relative to outside [27]. We also used Pearson's chi-square tests and two-tailed unequal variance $t$-tests to determine whether the characteristics of suicide victims that fell within the identified spatial clusters were significantly different from the state distribution. For the purely spatial analysis, a discrete Poisson probability model was used to scan for non-overlapping geographical areas (counties) with statistically significant high rates of suicide, using a maximum spatial cluster size of $50 \%$ of the total population at risk, as recommended by Kulldorff [24].

Further, high-risk temporal trends were investigated using the temporal scan statistic [25]. The temporal scan statistic uses a window that moves in one dimension, time, to identify a time period where suicide risk was higher than outside that time period. For the purely temporal analysis, we used a discrete Poisson probability model using a maximum temporal cluster size of 1-year and a 1-year time aggregation.

For statistical inference, 19,999 Monte Carlo replications were performed for all analyses, and the null hypothesis of no clusters was rejected at a probability $(p)$ value of $\leq 0.05$. All analyses were implemented in SatScan and adjusted for age $(10-14,15-19,20-24, \ldots \geq$ 85 ) and gender distributions at the county level for each individual year from 1999 to 2008 using population estimates derived from the US Census Bureau's Population Estimates Program obtained from the Surveillance, Epidemiology, and End Results (SEER) Program at the National Cancer Institute [29]. Cartographic displays of spatial clusters were made using ArcGIS 10 [21].

\section{Results}

\section{Descriptive epidemiology of suicide mortality}

Of the 5,551 suicide deaths abstracted from death certificates from the Kentucky Office of Vital Statistics between 1999 and 2008, 5,237 were used in our analyses after applying our exclusion criteria (see Exclusion Criteria in Figure 1). The excluded cases where the underlying cause of death did not match the manner of death (153 cases) appeared to be differentially distributed by year, where 128 (84\%) of those excluded cases occurred in 2000 and 2001. Among the other excluded cases, no apparent differential patterns were present.

Differences in age, marital status, year, seasons, and suicide method among suicide victims by gender are shown in Table 1. There were 4,313 (82\%) male suicide cases. The average age of suicide victims was 45.4 years, with significant differences between males (45.6 years old) and females (44.3 years old). Among age categories, males and females also showed significant differences $(p$ $<0.001)$. There were also significant differences by marital status, as $31 \%$ of females were divorced versus $22 \%$ of males $(p<0.001)$. Overall, $42 \%$ of all cases were married, $26 \%$ were single or never married, $24 \%$ were divorced, and $7 \%$ were widowed. Males and females differed significantly in the suicide method ( $p<0.001$ ), where $34.1 \%$ of female victims used self poisoning versus $7.7 \%$ of male victims. Male suicide victims used firearms with a greater frequency than females (71.1\% vs $48.8 \%)$. Overall, 3,517 $(67.2 \%)$ suicides were firearm related.

Figure 2 displays age adjusted male and female cumulative suicide incidence rates by year along with total suicides by year. The average male cumulative incidence rate from 1999 to 2008 was 20.9 per 100,000 persons, while the average female cumulative incidence rate was 4.3 per 100,000 persons.

\section{Spatial distribution of suicide}

The annual median SEB smoothed rate was 12.7 per 100,000 persons (range: $1-20.9$ ) (Figure 3). The counties with the highest SEB suicide mortality rates (greater than 17.6 suicides per 100,000) included Carlisle (17.7 suicides per 100,000), Hickman (17.9 suicides per $100,000)$, Ballard (18.4 suicides per 100,000), Wolfe (20.7 suicides per 100,000), and Gallatin (20.9 suicides per 100,000) (Figure 3).

\section{Spatial and temporal clusters of suicide}

Two significant $(p<0.05)$ high-risk spatial clusters of suicide were identified (Table $2 \&$ Figure 4 ). The most likely high-risk spatial cluster of suicide comprised seven counties (Ballard, Carlisle, Graves, Hickman, Livingston, Marshall, and McCracken). Populations within the counties of the most likely cluster are at a $38 \%$ greater risk (relative risk, $\mathrm{RR}=1.38 ; p=0.0029$ ) of suicide than outside the cluster (Table 2 \& Figure 4). Additionally, the most likely high-risk spatial cluster had an estimated 19.8 suicides per 100,000 persons annually. A secondary high-risk spatial cluster was found among 
Table 1 Characteristics of suicide cases in Kentucky, 1999-2008

\begin{tabular}{|c|c|c|c|c|}
\hline Variable & Male & Female & Total & Pearson $\times{ }^{2}(\mathrm{df})$ \\
\hline Suicide (row\% of total) & $4,313(82)$ & $924(18)$ & $5,237(100)$ & \\
\hline Average Age $(S D)^{*}$ & $45.6(18.0)$ & $44.3(15.4)$ & $45.4(17.6)$ & $-2.32, p=0.0203(1,533)$ \\
\hline Age Categories (column \% of sex specific total) & & & & $56.646, p=0.001(15)$ \\
\hline $10-14$ yrs & $20(0.46)$ & $5(0.54)$ & $25(0.47)$ & \\
\hline $15-19$ yrs & $183(4.2)$ & $42(4.5)$ & $225(4.3)$ & \\
\hline $20-24$ yrs & $334(7.7)$ & $45(4.9)$ & $379(7.2)$ & \\
\hline $25-29$ yrs & $377(8.7)$ & $70(7.6)$ & $447(8.5)$ & \\
\hline $30-34$ yrs & $382(8.9)$ & $79(8.5)$ & $461(8.8)$ & \\
\hline $35-39$ yrs & $454(10.5)$ & $113(12.2)$ & $567(10.8)$ & \\
\hline $40-44$ yrs & $484(11.2)$ & $137(14.8)$ & $621(11.9)$ & \\
\hline $45-49$ yrs & $472(10.9)$ & $116(12.6)$ & $588(11.2)$ & \\
\hline $50-54$ yrs & $385(8.9)$ & $97(10.5)$ & $482(9.2)$ & \\
\hline $55-59$ yrs & $284(6.6)$ & $81(8.8)$ & $365(7.0)$ & \\
\hline $60-64$ yrs & $212(4.9)$ & $46(5.0)$ & $258(4.9)$ & \\
\hline $65-69$ yrs & $189(4.4)$ & $32(3.5)$ & $221(4.2)$ & \\
\hline 70-74 yrs & $156(3.6)$ & $22(2.4)$ & $178(3.4)$ & \\
\hline 75-79 yrs & $144(3.3)$ & $18(1.9)$ & $162(3.1)$ & \\
\hline $80-84$ yrs & $138(3.2)$ & $14(1.5)$ & $152(2.9)$ & \\
\hline $85-98$ yrs & $99(2.3)$ & $7(0.76)$ & $106(2.0)$ & \\
\hline Marital Status (column \% of sex spepific total) & & & & $47.840, p=0.001(4)$ \\
\hline Divorced & $966(22)$ & $291(31)$ & $1,257(24)$ & \\
\hline Married & $1,850(43)$ & $357(39)$ & $2,207(42)$ & \\
\hline Single or Never Married & $1,180(27)$ & $189(20)$ & $1,369(26)$ & \\
\hline Widowed & $296(7)$ & $80(9)$ & $376(7)$ & \\
\hline Not Classified & $21(0.5)$ & $7(0.8)$ & $28(0.5)$ & \\
\hline Year (column \% of sex specific) & & & & $3.668, p=0.932(9)$ \\
\hline 1999 & $382(8.9)$ & $78(8.4)$ & $460(8.8)$ & \\
\hline 2000 & $339(7.9)$ & $68(7.4)$ & $407(7.8)$ & \\
\hline 2001 & $370(8.6)$ & $88(9.5)$ & $458(8.7)$ & \\
\hline 2002 & $433(10.0)$ & $89(9.6)$ & $522(10.0)$ & \\
\hline 2003 & $458(10.6)$ & $95(10.3)$ & $553(10.6)$ & \\
\hline 2004 & $450(10.4)$ & $92(10.0)$ & $542(10.3)$ & \\
\hline 2005 & $457(10.6)$ & $109(11.8)$ & $566(10.8)$ & \\
\hline 2006 & $497(11.5)$ & $97(10.5)$ & $594(11.3)$ & \\
\hline 2007 & $479(11.1)$ & $106(11.5)$ & $585(11.2)$ & \\
\hline 2008 & $448(10.4)$ & $102(11.0)$ & $550(10.5)$ & \\
\hline Seasons (column \% of sex specific total) & & & & $0.541, p=0.910$ \\
\hline Fall & $1,016(23.6)$ & $225(24.3)$ & $1,241(23.7)$ & \\
\hline Spring & $1,145(26.5)$ & $236(25.5)$ & $1,381(26.4)$ & \\
\hline Summer & $1,131(26.2)$ & $241(26.1)$ & $1,372(26.2)$ & \\
\hline Winter & $1,021(23.7)$ & $222(24.0)$ & $1,243(23.7)$ & \\
\hline Suicide method (Column \% of sex specific total) & & & & $492.01, p<0.001(3)$ \\
\hline Self-poisoning (X60-X69) & $333(7.7)$ & $315(34.1)$ & $648(12.4)$ & \\
\hline Hanging, strangulation, suffocation, drowning and submersion (X70-X71) & $777(18.0)$ & $127(13.7)$ & $904(17.3)$ & \\
\hline Firearm (X72-X74) & $3,066(71.1)$ & $451(48.8)$ & $3,517(67.2)$ & \\
\hline All other methods (X75-X84, Y87) & $137(3.2)$ & $31(3.4)$ & $168(3.2)$ & \\
\hline
\end{tabular}

${ }^{*}$ t-test for unequal variances used 


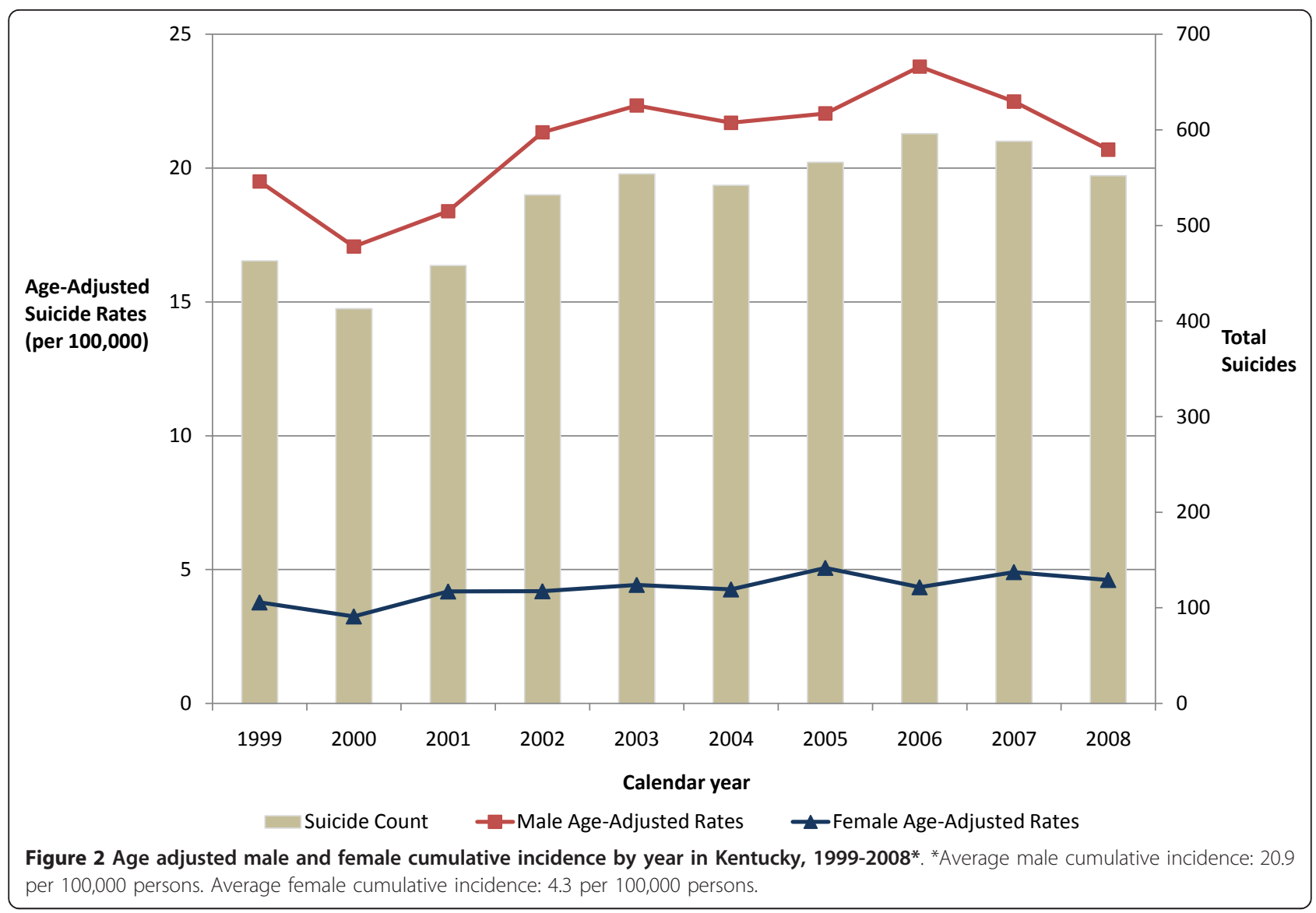

eight counties (Breckinridge, Daviess, Grayson, Hancock, Henderson, McLean, Meade, Ohio). This cluster had a $24 \%$ increased risk ( $R R=1.24, p=0.0324)$ of suicide than outside the cluster. This secondary cluster of high risk had an estimated 17.8 suicides per 100,000 persons annually (Table 2 \& Figure 4).

The purely temporal cluster analysis revealed that 2006 experienced a greater than expected number of suicides, with a marginal significantly higher risk of $12 \%$ compared to the other years $(\mathrm{RR}=1.12, p=0.04415)$ (Table 2).

\section{Descriptive epidemiology of high risk spatial clusters}

Table 3 compares the most likely and secondary spatial clusters to the rest of Kentucky. Only variables that had significant differences inside versus outside clusters are included in the table. The average age within the most likely spatial cluster was statistically different from the rest of Kentucky ( 48.9 yrs vs. 45.2 yrs) $(p<0.01)$, as was suicide cases by age categories $(\mathrm{p}=0.02)$. This was also the case for the average age of males within the most likely cluster (49.3 yrs) versus outside the cluster (45.4 yrs) $(p<0.01)$. Also, $19 \%$ of suicides within the secondary spatial cluster used poisoning as the method of suicide, while only $12 \%$ used poisoning outside the cluster $(p<0.001)$. Though average age was not significantly different within versus outside the secondary cluster, suicide cases by age categories for within versus outside the cluster was significant $(p=0.009)$.

The cumulative incidence inside the most likely cluster was 17.6 per 100,000 persons (range 12.4-21.6) while outside the cluster the rate was 12.4 per 100,000 persons (range 0-27.6). The cumulative incidence inside the secondary high-risk spatial cluster was 14.5 per 100,000 persons (range 10.2-18.2) (Table 3).

\section{Discussion}

We investigated the spatial epidemiology of suicides in Kentucky as reported in death certificate data files from the Kentucky Office of Vital Statistics between 1999 and 2008 using scan statistics and descriptive epidemiological methods. The results show evidence of hotspots of suicides across Kentucky counties, and describe the differences in suicide characteristics between genders, and for cases inside and outside high-risk spatial clusters. Further, when the purely spatial cluster analysis, SEB map, and cumulative incidence rates are jointly examined, they bolster the evidence of the existence of a 


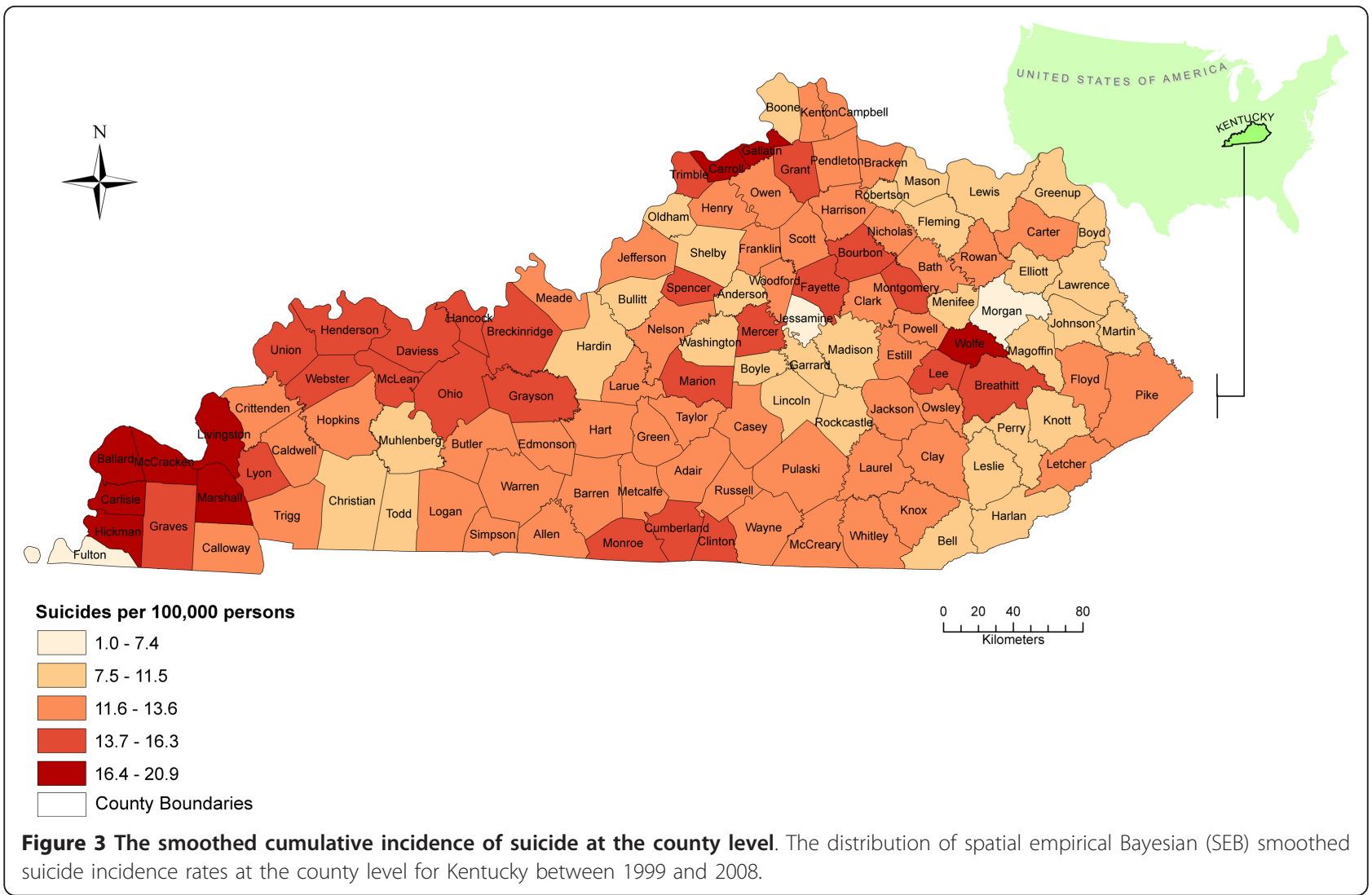

high-risk suicide cluster in western Kentucky. To our knowledge this is the first study to investigate spatial and temporal patterns of suicide mortality at the county level in the US. This study allows for a better understanding of where to target resources and prevention efforts at the county level to reduce the burden of suicide in areas of greatest risk [30,31].

Moreover, suicide victim characteristics within the two spatial clusters allow for more targeted prevention efforts. For example, there is a moderately older age group of victims in the most likely cluster, and a greater proportion of 40-44 year old suicide victims inside the secondary cluster compared to outside the cluster. In addition, suicide cases inside the secondary cluster are more likely to self-poison than outside the cluster. Although our results reveal that females are more likely to self-poison than males (and this agrees with national data) [1], there were not significantly more female suicides inside the secondary cluster than outside. These divergent characteristics of suicide cases inside versus

Table 2 Purely spatial and temporal significant clusters of suicides in Kentucky counties, 1999-2008

\begin{tabular}{|c|c|c|c|c|c|c|c|c|c|}
\hline Type & Counties & $\begin{array}{l}\text { Observed } \\
\text { cases }\end{array}$ & $\begin{array}{l}\text { Excepted } \\
\text { cases }\end{array}$ & Population & $\begin{array}{l}\text { Annual } \\
\text { cases/ } \\
100,000 \\
\text { Persons }\end{array}$ & $\begin{array}{l}\text { Relative } \\
\text { risk (RR) }\end{array}$ & $\begin{array}{l}p \text {-Value } \\
\text { (Controlling for } \\
\text { age and sex) }\end{array}$ & $\begin{array}{l}\text { Log- } \\
\text { likelihood } \\
\text { ratio }\end{array}$ & $\begin{array}{l}\text { Time } \\
\text { Frame }\end{array}$ \\
\hline \multicolumn{10}{|l|}{$\begin{array}{l}\text { Purely } \\
\text { Spatial }\end{array}$} \\
\hline $\begin{array}{l}\text { Most } \\
\text { likely }\end{array}$ & $\begin{array}{c}\text { Ballard, Carlisle, Graves, } \\
\text { Hickman, Livingston, Marshall, } \\
\text { McCracken }\end{array}$ & 283 & 207.66 & 141,345 & 19.8 & 1.38 & 0.0029 & 12.83 & $\begin{array}{l}1999- \\
2008\end{array}$ \\
\hline Secondary & $\begin{array}{c}\text { Breckinridge, Daviess, Grayson, } \\
\text { Hancock, Henderson, McLean, } \\
\text { Meade, Ohio }\end{array}$ & 383 & 313.75 & 215,991 & 17.8 & 1.24 & 0.0324 & 7.62 & $\begin{array}{l}1999- \\
2008\end{array}$ \\
\hline \multicolumn{10}{|l|}{$\begin{array}{c}\text { Purely } \\
\text { Temporal }\end{array}$} \\
\hline $\begin{array}{l}\text { Most } \\
\text { likely }\end{array}$ & All & 594 & 535.82 & - & 16.1 & 1.12 & 0.04415 & 3.41 & 2006 \\
\hline
\end{tabular}




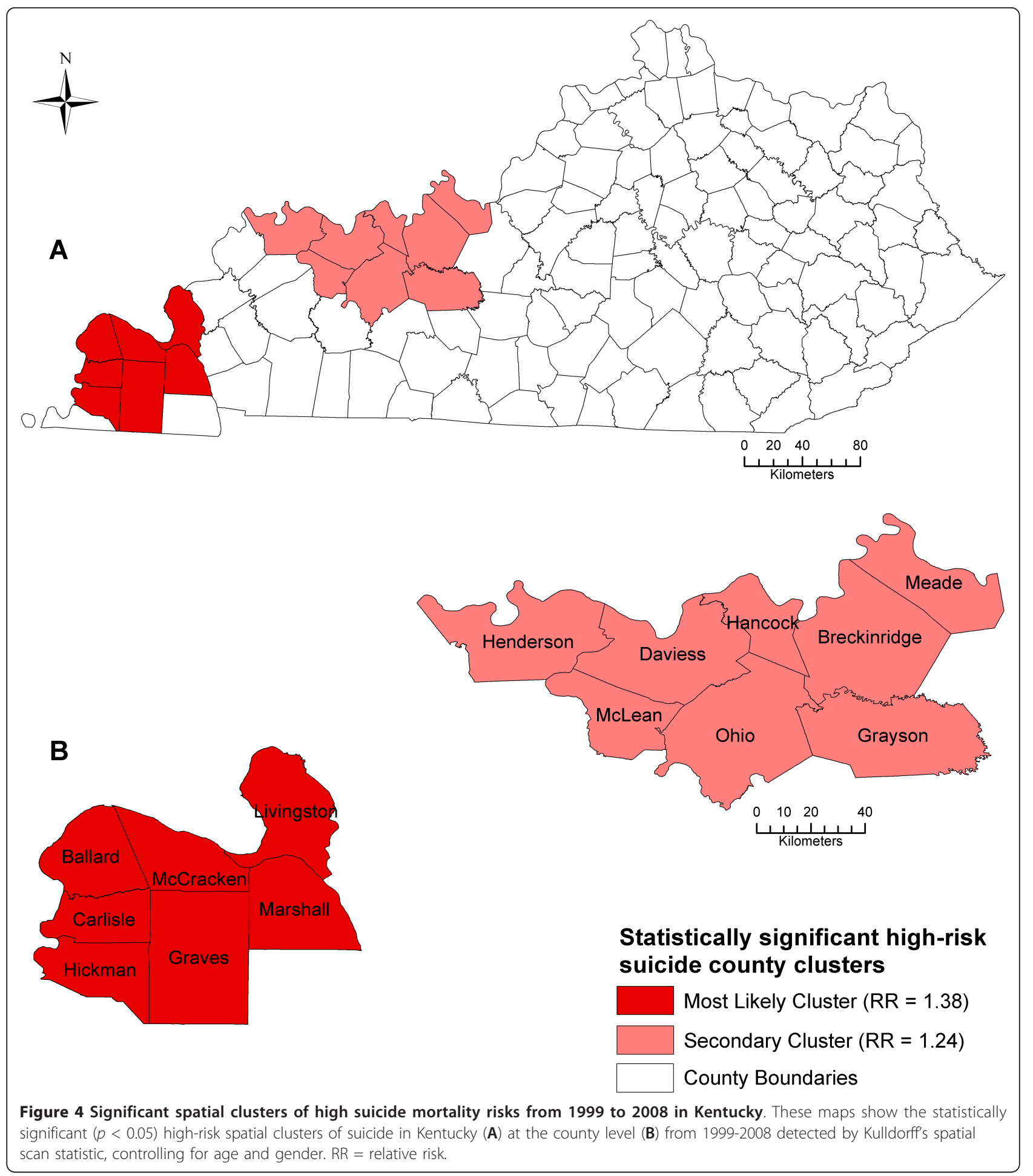

outside clusters can inform interventions and guide future studies. Suicide risk was also found to be highest in 2006, providing evidence that suicide has been gradually increasing in Kentucky since 1999.

Our study differs from Exeter and Boyle's (2007) Scotland suicide cluster analysis in several ways [10]. Exeter and Boyle's study, which was limited to young adult suicides (15 to 44 years old), found high risk clusters in Glasgow, Scotland, across three time periods with relative risks ranging from 1.53 to 2.41 , while our study revealed clusters with relative risks ranging from 1.24 to 1.38. Unlike our study, where $67 \%$ of suicides were 
Table 3 Descriptive characteristics of suicide cases inside and outside both significant spatial high-risk suicide clusters

\begin{tabular}{|c|c|c|c|c|c|c|}
\hline & $\begin{array}{l}\text { Within Most Likely High- } \\
\text { Risk Spatial Cluster } \\
\text { (column \% of Suicides } \\
\text { within cluster) }\end{array}$ & $\begin{array}{l}\text { Rest of Kentucky } \\
\text { (column \% of } \\
\text { Suicides outsides } \\
\text { outside cluster) } \\
\end{array}$ & $\begin{array}{l}\text { Pearson } \\
\chi^{2}(\mathrm{df})\end{array}$ & $\begin{array}{l}\text { Within Secondary High- } \\
\text { risk Spatial Cluster } \\
\text { (column \% of Suicides } \\
\text { within cluster) }\end{array}$ & $\begin{array}{l}\text { Rest Kentucky } \\
\text { (column \% of } \\
\text { Suicides outside } \\
\text { cluster) }\end{array}$ & $\begin{array}{l}\text { Pearson } \\
\chi^{2} \text { (df) }\end{array}$ \\
\hline Counties & $\begin{array}{l}\text { Ballard, Carlisle, Graves, } \\
\text { Hickman, Livingston, } \\
\text { Marshall, McCracken }\end{array}$ & - & & $\begin{array}{l}\text { Breckinridge, Daviess, } \\
\text { Grayson, Hancock, } \\
\text { Henderson, McLean, } \\
\text { Meade, Ohio }\end{array}$ & & \\
\hline \multicolumn{7}{|l|}{$A g e^{*}$} \\
\hline Average age (SD) & 48.9 (18.8) & $45.2(17.5)$ & $\begin{array}{l}3.190, p \\
<0.01 \\
(309)\end{array}$ & 45.5 (16.1) & $45.4(17.7)$ & $\begin{array}{l}-0.09, p \\
=0.932 \\
(459)\end{array}$ \\
\hline $\begin{array}{l}\text { Average Age of } \\
\text { Males (SD) }\end{array}$ & $49.3(19.2)$ & $45.4(18.0)$ & $\begin{array}{l}2.92, p< \\
0.01 \\
(250)\end{array}$ & $45.7(16.7)$ & $45.6(18.2)$ & $\begin{array}{l}-0.0633 \\
p= \\
0.950 \\
(382)\end{array}$ \\
\hline $\begin{array}{l}\text { Average Age of } \\
\text { Females (SD) }\end{array}$ & $47.1(17)$ & $44.1(15.3)$ & $\begin{array}{l}-1.12, p \\
=0.267 \\
(57)\end{array}$ & $44.3(12.4)$ & 44.3 (15.6) & $\begin{array}{l}0.023, p \\
=0.982 \\
(75)\end{array}$ \\
\hline \multicolumn{7}{|l|}{ Age category } \\
\hline $10-14$ yrs & $1(0.35)$ & $24(0.48)$ & $\begin{array}{l}28.264, p \\
=0.020 \\
(15)\end{array}$ & $0(0)$ & $25(0.52)$ & $\begin{array}{l}30.783, p \\
=0.009 \\
(15)\end{array}$ \\
\hline 15-19 yrs & $15(5.3)$ & $210(4.2)$ & & $12(3.1)$ & $213(4.4)$ & \\
\hline $20-24$ yrs & $16(5.6)$ & $363(7.3)$ & & $21(5.5)$ & $358(7.4)$ & \\
\hline $25-29$ yrs & $13(4.6)$ & $434(8.8)$ & & $30(7.8)$ & $417(8.6)$ & \\
\hline $30-34$ yrs & $19(6.7)$ & $442(8.9)$ & & $32(8.4)$ & $429(8.4)$ & \\
\hline $35-39$ yrs & $28(9.9)$ & 539 (10.9) & & $44(11.5)$ & $523(10.8)$ & \\
\hline $40-44$ yrs & $31(11.0)$ & $590(11.9)$ & & $66(17.2)$ & 555 (11.4) & \\
\hline $45-49$ yrs & $29(10.2)$ & 559 (11.3) & & $37(9.7)$ & $551(11.4)$ & \\
\hline $50-54$ yrs & $34(12.0)$ & $448(9.0)$ & & $48(12.5)$ & $434(8.9)$ & \\
\hline $55-59$ yrs & $23(8.1)$ & $342(6.9)$ & & $24(6.3)$ & $341(7.0)$ & \\
\hline $60-64$ yrs & $14(4.9)$ & $244(4.9)$ & & $23(6.0)$ & $235(4.8)$ & \\
\hline $65-69$ yrs & $13(4.6)$ & $208(4.2)$ & & $11(2.9)$ & $210(4.3)$ & \\
\hline 70-74 yrs & $10(3.5)$ & $168(3.4)$ & & $10(2.6)$ & $168(3.5)$ & \\
\hline 75-79 yrs & $13(4.6)$ & $149(3.0)$ & & $5(1.3)$ & $157(3.2)$ & \\
\hline $80-84$ yrs & $15(5.3)$ & $137(2.8)$ & & $14(3.7)$ & $138(2.8)$ & \\
\hline $85-98$ yrs & $9(3.2)$ & $97(2.0)$ & & $6(1.6)$ & $100(2.1)$ & \\
\hline Total Suicides & $283(100)$ & $4,954(100)$ & & $383(100)$ & $4854(100)$ & \\
\hline \multicolumn{7}{|l|}{ Suicide Method } \\
\hline $\begin{array}{l}\text { Self-poisoning (X60- } \\
\text { X69) }\end{array}$ & $34(12)$ & $614(12)$ & $\begin{array}{l}4.569, p \\
=0.206 \\
(3)\end{array}$ & $74(19)$ & $574(12)$ & $\begin{array}{l}21.027, p \\
<0.001 \\
(3)\end{array}$ \\
\hline $\begin{array}{l}\text { Hanging, } \\
\text { strangulation, } \\
\text { suffocation, } \\
\text { drowning and } \\
\text { submersion (X70- } \\
\text { X71) }\end{array}$ & $43(15)$ & $861(17)$ & & $55(14)$ & $849(17)$ & \\
\hline Firearm (X72-X74) & $202(71)$ & $3,315(67)$ & & $247(64)$ & $3,270(67)$ & \\
\hline $\begin{array}{l}\text { All other methods } \\
\text { (X75-X84, Y87) }\end{array}$ & $4(1)$ & $164(3)$ & & $7(2)$ & $161(3)$ & \\
\hline Total Suicides & $283(100)$ & $4,954(100)$ & & $383(100)$ & $4,854(100)$ & \\
\hline \multicolumn{7}{|l|}{$\begin{array}{l}\text { Cumulative incidence } \\
\text { rates per 100,000 persons }\end{array}$} \\
\hline Average (SD) & $17.6(2.9)$ & $12.4(4.1)$ & & $14.5(2.5)$ & $12.5(4.2)$ & \\
\hline Median & 18.5 & 12.3 & & 14.6 & 12.3 & \\
\hline Range & $12.4-21.6$ & $0-27.6$ & & $10.2-18.2$ & $0-27.6$ & \\
\hline
\end{tabular}

*t-test for unequal variances used 
firearm related (65\% for adults 15 to 44 years old), Exeter and Boyle found that $63 \%$ of suicides among young adults were from poisonings, hangings, strangulation and suffocation. In addition, Scotland's suicide rate among adults aged 15 to 44 years in 1999 to 2001 was 24.3 per 100,000 persons, which was markedly higher than Kentucky's suicide rate of 13.5 per 100,000 persons among adults aged 15 to 44 years during the same period [1]. This difference in suicide method and rates suggests that suicide may be better explained by other factors-such as low socioeconomic status [3,10], less access to mental health care [32], sudden unemployment [33], depression [34], and alcoholism [35]-than by firearm access alone [36], given that Scotland's suicide rate is higher than Kentucky's despite there being lower access to firearms in Scotland than Kentucky [37]. Thus, this comparison suggests that firearm availability may not be the sole driving force behind increased regional suicide rates. Both studies reveal that suicide does not occur randomly in space, and that the characteristics of suicide cases inside clusters tend to be different than outside; specifically in Scotland where suicide clusters have been explained by the concentration of socioeconomic deprivation [10].

\section{Strengths, limitations, and future research}

In addition to the previously mentioned advantages of using scan statistics over other epidemiology methods, scan statistics do not assume that observations are spatially independent, but rather test for spatial randomness, or in other words, spatial independence of the observations. An additional strength of this study is that it uses novel spatial techniques to provide ecological information on suicide risk, thus having the potential to guide interventions in those high-risk counties.

This study used data from death certificates which can be affected by errors. Pierce and Denison (2006) assessed place-of-residence errors on death certificates in only two Texas counties and found a $14 \%$ error rate in recording county of residence for deaths [38]. Within our dataset, cases where the underlying cause of death and the manner of death did not match were excluded. Further, excluded cases due to this discrepancy came mainly from 2000 and 2001. This differential distribution in excluded cases may have biased the temporal analysis results away from the null hypothesis. Although 2006 has the highest suicide incidence rate, this introduced bias may have inflated that excess risk because of the seemingly lower rates in 2000 and 2001. Additionally, suicide mortality may not reflect current prevention needs. This study also used county-level data, which does not discriminate among suicide mortality risk in different parts of the county.
We are inclined to recommend future studies be undertaken in the high-risk counties to identify reasons for the high rates observed. Although Exeter and Boyle's (2007) study found high-risk suicide clusters to be explained by greater social deprivation [10], implying that greater suicide risk is dependent on a relatively stable regional risk factor, several interventions such as physician education in depression recognition and treatment, along with greater restriction of access to lethal methods have been shown to be effective in reducing suicide rates [39]. It is important to note that since suicide is affected by sociocultural factors, effective interventions in a certain population may not work elsewhere [40]. Regardless, our study does offer evidence to support increasing availability and access to mental health care facilities, and targeted prevention efforts across the identified high-risk clusters in western Kentucky. Given that suicide is highly associated with poor mental health and depression [3,41], it is appropriate to make mental health facilities more available to provide services to those populations that most need it. We believe that future studies assessing suicide risk may provide more insight into regional-specific interventions that are most appropriate for western Kentucky.

In guiding future suicide spatial research, we recommend that individual-level circumstance data from the National Violent Death Reporting System (NVDRS) in Kentucky be linked to socioeconomic and demographic data, and vital statistics data to offer a richer understanding of those persons who define the cluster. It is also recommended that spatial analyses be performed using NVDRS suicide data at the census-tract level to allow comparisons between the county-level analysis and to offer a lower level (i.e., finer) visualization of suicide risk. This study also guides future small area analysis research: i.e., given that two high-risk suicide clusters have been identified, we recommend a spatial analysis limited to each cluster, with those high-risk counties divided into smaller census-tracts to identify those tracts within high-risk counties that are at greatest risk for suicide. Moreover, a further investigation determining the factors associated with high-risk clusters of suicide is recommended using regression analysis by linking various sociodemographic and environmental county (or census-tract) characteristics to the vital statistics data. This approach would offer an ecological understanding of the county-level (or census-tract) characteristics that explain suicide risk. We hypothesize that similar results may be found in Kentucky as in Glasgow, UK, and Queensland, Australia, where socioeconomic deprivation has been associated with high-risk suicide clusters $[10,11]$. Without more rigorous regression analyses, however, we would only be speculating as to what 
explains high-risk county clusters of suicide in Kentucky.

Beyond regional social deprivation, several other factors may be contributing to the higher rates of suicide in these relatively rural regions (i.e., all seven counties in the most likely cluster are rural, and three out of eight counties in the secondary cluster are rural) [42]. Specifically, rurality has been found to be a likely regional risk factor for suicide in the United States and Australia $[43,44]$. Rural populations have less access to mental health care facilities, putting those with mental health disorders at a greater risk for suicide than their urban counterparts $[44,45]$. Furthermore, data collected from the Kentucky Violent Death Reporting System (KVDRS) from 1999-2008 suggest that county-level unemployment may be statistically associated with higher rates of suicide (Sabrina Walsh, unpublished data).

\section{Conclusion}

This study found high-risk clusters of suicide in western Kentucky and demonstrated the usefulness of the combination and complementary nature of spatial statistics, cumulative incidence, relative risk, and SEB smoothed rates in identifying areas at highest risk for suicide. The findings can guide intervention efforts at the county level in Kentucky to reduce suicide in those areas at greatest risk.

\section{Abbreviations}

US: United States; WHO: World health organization; IRB: Institutional review board; ICD-10: International classification of diseases: 10th revision; CDC: Center's for disease control and prevention; SEB: Spatial empirical Bayesian; SEER: Surveillance: epidemiology: and end results; NVDRS: National violent death reporting system.

\section{Acknowledgements}

This study was supported by Cooperative Agreement CE09-904 from the Centers for Disease Control and Prevention. Its contents are solely the responsibility of the authors and do not necessarily represent the official views of CDC. We would also like to thank Amanda Thaxton for assisting with data acquisition.

\section{Author details}

${ }^{1}$ Department of Epidemiology, College of Public Health, University of Kentucky, Lexington, Kentucky, USA. ${ }^{2}$ Department of Health Services Management, College of Public Health, University of Kentucky, Lexington, Kentucky, USA. ${ }^{3}$ Department of Biomedical \& Diagnostic Sciences, College of Veterinary Medicine, University of Tennessee, Knoxville, Tennessee, USA.

\section{Authors' contributions \\ DMS conceived the research idea, study design, performed all analyses, managed data, interpreted results, and wrote the manuscript. AO was involved in study design, results interpretation, and editing of the manuscript. AB drafted the Introduction and was involved in data acquisition. SW was involved in data acquisition, results interpretation, as well as review and editing of the manuscript. All authors certify that they have participated sufficiently in the research to believe in its overall validity and have read and approved the final manuscript.}

\section{Competing interests}

The authors declare that they have no competing interests.
Received: 18 October 2011 Accepted: 8 February 2012

Published: 8 February 2012

\section{References}

1. Kochanek KD, Xu J, Murphy SL, Minino AM, Kung HC: Deaths: preliminary data for 2009. National Vital Statistics Reports. Centers for Disease Control and Prevention 2011, 59:1-51.

2. Centers for Disease Control and Prevention (CDC): Web-based Injury Statistics Query and Reporting System (WISQARS). Data \& Statistics (WISQARSTM): Cost of Injury Reports. 2005, Retrieved August 8, 2011, from http://wisqars.cdc.gov:8080/costT/.

3. Krug EG, Dahlberg LL, Mercy JA, Zwi AB, Lozano R: World report on violence and health. Self-directed violence Geneva, Switzerland: World Health Organization; 2002.

4. Kulldorff M, Athas WF, Feuer EJ, Miller BA, Key C: Evaluating cluster alarms: a space-time scan statistic and brain cancer in Los Alamos, New Mexico. Am J Public Health 1998, 88:1377-1380.

5. Wylie $\mathrm{L}$, Cabral T, Jolly AM: Identification of networks of sexually transmitted infection: a molecular, geographic, and social network analysis. J linfect Dis 2005, 191(6):899-906.

6. Hsu CE, Jacobson H, Mas FS: Evaluating the disparity of female breast cancer mortality among racial groups - a spatiotemporal analysis. Int $J$ Health Geogr 2004, 3:4.

7. Haddow AD, Bixler D, Odoi A: The spatial epidemiology and clinical features of reported cases of La Crosse Virus infection in West Virgina from 2003 to 2007. BMC Infect Dis 2011, 11:29.

8. Odoi A, Martin SW, Michel P, Holt J, Middleton D, Wilson J: Geographical and temporal distribution of human giardiasis in Ontario, Canada. Int $J$ Health Geogr 2003, 2(1):5

9. Bilancia M, Fedespina A: Geographical clustering of lung cancer in the province of Lecce, Italy: 1992-2001. Int J Health Geographics 2009, 8:40.

10. Exeter DJ, Boyle PJ: Does young adult suicide cluster geographically in Scotland? J Epidemiol Community Health 2007, 61(8):731-736.

11. Qi X, Tong S, Hu W: Spatial distribution of suicide in Queensland, Australia. BMC Psychiatry 2010, 10:106.

12. Centers for Disease Control and Prevention (CDC): Uniform definitions for self-directed violence. 2011, Available at http://www.cdc.gov/ ViolencePrevention/pub/selfdirected_violence.html. Accessed August 20, 2011.

13. Abramson $\mathrm{JH}$ : WINPEPI updated: computer programs for epidemiologists, and their teaching potential. Epidemiologic Perspectives \& Innovations 2011, 8:1.

14. SAS Institute: SAS 9.3. Cary, North Carolina, USA: SAS Institute Inc; 2011.

15. Microsoft Cooporation: Microsoft Office Excel 2007. Microsoft Office, USA.

16. Waller L, Gotway C: Mapping smoothed rates and probabilities. Applied Statial Statistics for Public Health Data Hoboken, New Jersey: John Wiley \& Sons, Inc; 2004, 86-104.

17. Clayton D, Bernardinelli L: Bayesian methods for mapping disease risk. In Geographical and Environmental Epidemiology. Edited by: Elliott CJ, English D, Stern R. Oxford: Oxford University Press; 1997:206-220.

18. Anselin L: GeoDa Version 0.95i IL, USA: Spatial Analysis Lab, University of Illinois Urbana-Champaign; 2003.

19. Anselin L, Syabri I, Kho Y: GeoDa: an introduction to spatial data analysis. Geogr Anal 2006, 38(1):5-22.

20. US Census Bureau: Census TIGER/Line ${ }^{\circledR}$ Shapefiles. 2010, Available at http://www.census.gov/cgi-bin/geo/shapefiles2010/main. Accessed May 20, 2011.

21. ESRI: ArcInfo GIS v10 Redlands, CA, USA: Environmental Systems Research Institute, Inc; 2011.

22. Brewer CA: ColorBrewer 2.0., Available at http://colorbrewer2.org. Accessed May 20, 2011.

23. Jenks $\mathrm{G}$ : The data concept in statistical mapping. The International Yearbook of Cartography 1967, 7:186-190.

24. Kulldorff M: A spatial scan statistic. Communications in Statistics: Theory and Methods 1997, 26:1481-1496.

25. Kulldorff M: SatScan v9.1.1: Software for the spatial and space-time scan statistics Information Management Services, Inc, Silver Spring, Maryland, USA; 2011.

26. Kulldorff $M$, Athas WF, Feuer EJ, Miller BA, Key CR: Evaluating cluster alarms: a space-time scan statistic and brain cancer in Los Alamos, New Mexico. Am J Public Health 1998, 88:1377-1380. 
27. Kulldorff M, Nagarwalla N: Spatial disease clusters: detection and inference. Stat Med 1995, 14:799-810.

28. Dwass M: Modified randomization tests for non-parametric hypothesis. Ann Math Stat 1957, 28:181-187.

29. US Census Bureau Population Estimates Program: Surveillance, Epidemiology, and End Results (SEER) Program at the National Cancer Institute: US Population Data 1969-2009. 2011, Available at http://seer. cancer.gov/popdata/. Accessed May 20, 2011.

30. Holowaty EJ, Norwood TA, Wanigaratne S, Abellan JJ, Beale L: Feasibility and utility of mapping disease risk at the neighbourhood level within a Canadian public health unit: an ecological study. Int J Health Geogr 2010, 9:21.

31. Odoi A, Martin SW, Michel P, Middleton D, Holton J, Wilson J: Investigation of clusters of giardiasis using GIS and a spatial scan statistic. Int J Health Geogr 2004, 3:11.

32. Tondo L, Albert MJ, Baldessarini RJ: Suicide rates in relation to health care access in the United States: an ecological study. J Clin Psychiatry 2006, 67(4):517-523.

33. Beautrais AL, Joyce PR, Mulder RT: Unemployment and serious suicide attempts. Psychol Med 1998, 28:209-218.

34. Beck AT, Brown G, Berchick RJ, Stewart BL, Steer RA: The relationship between hopelessness and ultimate suicide: a replication with psychiatric outpatients. Am J Psychiatry 1990, 147:190-195.

35. Murphy GE, Wetzel RD: The life-time risk of suicide in alcoholism. Arch Gen Psychiatry 1990, 47:383-392.

36. Kates $\mathrm{DB}$, Mauser $\mathrm{G}$ : Would banning firearms reduce murder and suicide? a review of international and some domestic evidence. Harvard Journal of Law \& Public Policy 2007, 30(2):649-694.

37. Handguns to be banned in the UK: BBC on this day: October 16. 1996, Available at: http://news.bbc.co.uk/onthisday/hi/dates/stories/october/16/ newsid_3110000/3110949.stm. Accessed October 7, 2011.

38. Pierce RJ Jr, Denison AV: Place-of-residence errors on death certificates for two contiguous U.S. counties. Popul Health Metr 2006, 4:6.

39. Mann JJ, Apter A, Bertolote J, Beatrais A, Currier D, Haas A, et al: Suicide prevention strategies: a systematic review. JAMA 2005, 294(16):2064-2074.

40. Bertolote JM: Suicide prevention: at what level does it work? World Psychiatry 2004, 3(3):147-151.

41. Blumenthal SJ: Suicide: a guide to risk factors, assessment, and treatment of suicidal patterns. Med Clin North Am 1988, 72:937-971.

42. United States Department of Agriculture, Economic Research Service: Ruralurban continuum codes for KY. 2003, Available at http://www.ers.usda. gov/data/ruralurbancontinuumcodes/2003. Accessed December 26, 2011.

43. Centers for Disease Control and Prevention (CDC): Web-based Injury Statistics Query and Reporting System (WISQARS). National Center for Injury Prevention and Control. Fatal injury mapping, United States Counties 2000-2006, Retrieved December 26, 2011, from http://wisqars.cdc.gov:8080/ cdcMapFramework/mapModuleInterface.jsp.

44. Singh GP, Siahpush M: Increasing rural-urban gradients in US suicide mortality, 1970-1997. Am J Public Health 2002, 92:1161-1167.

45. Caldwell TM, Jorm AF, Dear KBG: Suicide and mental health in rural, remote and metropolitan areas in Australia. Med J Aust 2004, 181:S10-S14.

\section{Pre-publication history}

The pre-publication history for this paper can be accessed here: http://www.biomedcentral.com/1471-2458/12/108/prepub

doi:10.1186/1471-2458-12-108

Cite this article as: Saman et al:: Does place of residence affect risk of suicide? a spatial epidemiologic investigation in Kentucky from 1999 to 2008. BMC Public Health 2012 12:108.

\section{Submit your next manuscript to BioMed Central and take full advantage of:}

- Convenient online submission

- Thorough peer review

- No space constraints or color figure charges

- Immediate publication on acceptance

- Inclusion in PubMed, CAS, Scopus and Google Scholar

- Research which is freely available for redistribution

Submit your manuscript at www.biomedcentral.com/submit
Biomed Central 